Institutions

Markets

Technologies

IMT

INSTITUTE

FOR ADVANCED

STUDIES

LUCCA

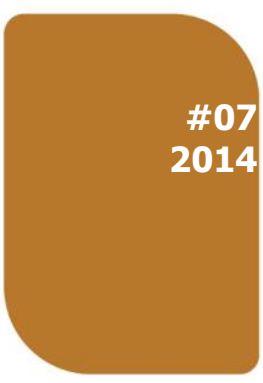

ISSN 2279-6894

IMT LUCCA EIC WORKING

PAPER SERIES 07

\title{
Assessing the solvency of insurance portfolios via a continuous time cohort model
}

Petar Jevtić

Luca Regis 
ISSN 2279-6894

IMT LUCCA EIC WORKING PAPER SERIES \#07/2014

(C) IMT Institute for Advanced Studies Lucca

Piazza San Ponziano 6, 55100 Lucca

\section{Assessing the solvency of insurance portfolios via a continuous time cohort model}

\section{Petar Jevtić}

Department of Mathematics and Statistics, McMaster University

\section{Luca Regis}

AXES Research Unit, IMT Institute for Advanced Studies Lucca 


\title{
Assessing the solvency of insurance portfolios via a continuous time cohort model*
}

\author{
Petar Jevtić ${ }^{\dagger}$ Luca Regis ${ }^{\ddagger}$ \\ July 7, 2014
}

\begin{abstract}
This paper evaluates the solvency of a portfolio of assets and liabilities of an insurer subject to both longevity and financial risks. Liabilities are evaluated at fair-value and, as a consequence, interestrate risk can affect both the assets and the liabilities. Longevity risk is described via a continuous-time cohort model. We evaluate the effects of natural hedging strategies on the risk profile of an insurance portfolio in run-off. Numerical simulations, calibrated to UK historical data, show that systematic longevity risk is of particular importance and needs to be hedged. Natural hedging can improve the solvency of the insurer, if interest-rate risk is appropriately managed. We stress that asset allocation choices should not be independent of the composition of the liability portfolio of the insurer.
\end{abstract}

Keywords: longevity risk; natural hedging; continuous-time cohort models for longevity; solvency of insurance portfolios; solvency requirements; longevity and interest-rate risk.

JEL Classification: G22, G32.

*The authors would like to thank Tom Hurd, Hong Li, Elisa Luciano, Stephane Loisel, Elena Vigna, seminar participants at McMaster University and conference participants at the Afmath Conference 2014 (Brussels), the Netspar International Pension Workshop (Venice), the 8th Conference in Actuarial Science and Finance (Samos), the First International Conference on Actuarial Science and Quantitative Finance (Bogotá) for their helpful comments.

${ }^{\dagger}$ McMaster University, Department of Mathematics and Statistics, Hamilton, Ontario L8S 4K1, Canada; pjevtic@math.mcmaster.ca.

‡IMT Institute for Advanced Studies Lucca; AXES Research Unit; Piazza San Francesco, 1955100 Lucca, Italy; luca.regis@imtlucca.it. 


\section{Introduction}

The assets and liabilities owned by insurance companies and pension funds are subject to various sources of uncertainty, making the assessment of their risk profile and solvency a challenging task. Regulators - for example, through the Solvency II Directive - are aiming at steering insurance companies towards a comprehensive accounting of the risks affecting their portfolios. This increasing attention to the soundness of risk management practices is enhancing the level of complexity of required valuation models, particularly in the context of the Own Risk Solvency Assessment (ORSA) process.

A proper assessment of the solvency of a portfolio requires the modeling of many risk sources. As companies invest in bonds and in the stock market, equity risk, together with interest-rate risk, affect the asset side. On the liabilities side, regulation in the Solvency II framework and the recent International Accounting Standards (IAS) have boosted the importance of market fair-valuation. From a risk management perspective, this entails both longevity risk and interest-rate risk assessment. The recent population ageing phenomenon has clearly highlighted the exposure of annuity providers and life insurers to the uncertainty in mortality rates themselves (systematic longevity risk), coupled with the well-known randomness in the deaths of the policyholders in the portfolio (idiosyncratic longevity risk). Longevity risk, in both these dimensions, needs to be taken into account. It represents a relevant threat to the solvency of annuity providers and the hedging of its undiversifiable component has recently been investigated in the literature. Interest-rate risk impacts the value of liabilities, as they need to be discounted using the current term structure. As a consequence, the overall risk profile of the company is influenced by both the asset allocation strategy and the liability portfolio composition, and the choices regarding these two dimensions are deeply interconnected. However, in practice, quite surprisingly, liability hedging is still widely neglected. A recent Mercer (2013)'s survey highlights that only $26 \%$ of pension fund managers in the sample perform LDI (Liability Driven Investment) strategies of any kind, and that longevity risk is rarely managed.

This paper highlights the importance of managing longevity risk by assessing its relevance in an annuity portfolio. We explore the effectiveness of so-called natural hedging strategies, which mitigate systematic longevity risk by mixing annuities and life insurance policies. We focus on natural hedging as it could constitute a readily available and feasible alternative to the 
use of mortality derivatives, whose market, albeit slowly expanding (Blake et al. (2014)), is still lacking in volume and standardization. While hedging stategies using derivative products are very effective in theory (see Ngai and Sherris (2011), for instance), the lack of liquidity that their market experiences may cause adverse selection problems (Biffis and Blake (2013)) or inefficiencies (Luciano and Regis (2014)).

Natural hedging strategies of longevity risk have recently been studied. Cox and Lin (2007) first documented that insurance companies that mixed annuities and life insurance policies experience a comparative advantage with respect to annuity-only providers. On these grounds, and given that natural hedging is easy to implement and cheap to insurance companies, the academic literature has recently explored the implementation and effectiveness of such strategies. Wang et al. (2010) and Wang et al. (2013) developed immunization strategies, where mortality is described by means of discrete-time models. Gatzert and Wesker (2012) numerically analyzed the potential risk mitigation provided by the liability mix, under different investment strategies, finding that the overall risk of a company can be reduced considerably. These works, however, do not evaluate liabilities at fair-value. Stevens et al. (2011) highlighted the importance of considering the interactions between longevity risk and financial risks, as such an omission might lead to overestimation of the natural hedging potential. Luciano et al. (2012) proposed a Delta-Gamma hedging strategy, accounting for the effects of natural hedging on the interest-rate risk exposure of the company.

This paper is the first to propose an analysis of the effectiveness of natural hedging strategies in the context of an ALM model of the insurance company in which liabilities are evaluated at market values and affected by interest-rate and longevity risks alike. We couple a standard description of the financial market by means of the well-known Vasicek (1977) model with a parsimonious description of mortality risk via a continuous-time cohort based stochastic model, following Luciano and Vigna (2008). This choice, in addition to being reasonably accurate in describing the evolution of mortality and interest rates, allows us to obtain the fair-value reserves of liabilities and their sensitivities (Greeks) to relevant risk factors in closed form (Luciano et al. (2012)). This permits us to account for multiple risk sources, while considerably reducing the computational effort. Our analysis extends Hari et al. (2008), who focused - as we do - on the characteristics of the funding ratio of annuity providers. Apart from selecting a different mortality modelling strategy, we complement their analysis by introducing interest- 
rate risk uncertainty in our simulations and accounting for the presence of life insurance policies on the side of the liabilities.

Our numerical analysis, calibrated on UK-data, allows us to assess the impact of the liability mix, together with the asset mix, on the solvency and bankruptcy likelihood of a portfolio of insurance policies in run-off. First, it documents the relevant impact of systematic longevity risk on annuity portfolios. While interest-rate risk is the most relevant risk source at short horizons, systematic longevity risk largely affects the variability of portfolio value in the medium-long run and needs to be managed for solvency purposes. Second, we analyze the effects of natural Delta-hedging strategies as proposed by Luciano et al. (2012). They are effective in reducing longevity risk and in improving the solvency of an annuity portfolio, especially when it is welldiversified (i.e. large enough). When the additional interest-rate risk due to the introduction of the portfolio of life insurance policies is not hedged, the company can worsen its risk profile and experience higher bankruptcy likelihood in the long run. We thus highlight the importance of jointly determining asset allocation and liability mix choices.

The paper is organized as follows: in Section 2, we present our framework and describe our modelling of the risk sources. In Section 3, we present numerical results from our simulations, based on a calibrated example given the relevant UK data. Finally, in Section 4 we make conclusions and propose further research.

\section{Setup}

In order to properly provide an assessment of the risk profile of an insurance portfolio, it is necessary to provide a comprehensive view of the risks surrounding its assets and liabilities, both concerning demographic and financial aspects. In this section, we describe an asset-liability model of a company, including

1. interest-rate risk, due to the stochastic fluctuations of the short rate;

2. idiosyncratic longevity risk, due to the uncertainty in the death arrival times of the individuals;

3. systematic longevity risk, due to the unexpected changes in the mortality intensity of the pool of policyholders, and 
4. equity risk, due to the investment in the stock market.

While equity risk affects the asset side of the portfolio only - assuming that no participating policies are issued - the first three risk sources affect both the assets and liabilities, when the latter are evaluated on a market-consistent basis. While in principle we can have dependence between financial risks and longevity risk we will assume them to be independent. Each of these risk sources is described by continuous-time stochastic processes, which we appropriately discretize when simulating. Discretization is done at intervals of time-length $\Delta$, such that $t_{i}=t_{0}+i \Delta, i \in \mathbb{I}=\left\{1,2, \ldots, N_{0} \in \mathbb{N}\right\}$.

\subsection{Liabilities}

The liability portfolio of the insurer is composed of standard insurance policies: whole-life annuities (A) and temporary death contracts (D). We focus on a portfolio made by an homogeneous group $N_{A}$ of annuities $A(x, R)$, where $x$ is the cohort to which policyholders belong and $R$ is the level payment. This annuity portfolio may be complemented by an homogeneous group $N_{D}$ of death insurance contracts $D(x, Q, C)$, where $Q$ is the maturity and $C$ the insured amount. For simplicity, we consider that single premiums are paid at $t_{0}$ and we analyze the evolution of the portfolio in run-off, having thus no new policies issued after $t_{0}$. We denote by

$$
T_{A}^{O}(x, R)=\left\{t_{j}\right\}, j \in J_{A}^{O} \subset \mathbb{I}
$$

the set of known payment dates for the annuity $A(x, R)$ and, likewise,

$$
T_{D}^{O}(x, Q, C)=\left\{t_{j}\right\}, j \in J_{D}^{O} \subset \mathbb{I}
$$

the set of known (yearly) payment dates for the death contract $D(x, Q, C)$.

We now provide a description of the two risk sources affecting the liabilities' side, namely longevity risk and interest-rate risk.

\subsubsection{Longevity risk}

We model longevity risk following a well-established stream of literature (initiated by Milevsky and Promislow (2001)) and provide a continuous-time cohort-based description of mortality. The event of death of an individual is modelled through a Cox process, as the first jump time of a Poisson process 
with stochastic intensity. This intensity is generation dependent and belongs to the affine class (see Biffis (2005)). Generation $x$ mortality intensity follows a purely-diffusive Ornstein-Uhlenbeck (OU) process introduced by Luciano and Vigna (2008)

$$
d \lambda_{x}(t)=a_{x} \lambda_{x}(t) d t+\sigma_{x} d W_{x}^{\mathbb{P}}(t)
$$

where $a_{x}>0$ and $\sigma_{x} \geq 0$ and $W_{x}^{\mathbb{P}}$ is a Brownian Motion under the historical measure $\mathbb{P}$. Indeed, the intensity can theoretically become negative, but in practical applications we make sure that the probability of that event is negligible. Our modeling choice is motivated by the many attractive features of this process

- it is parsimonious, since it requires the estimation of two parameters per generation only,

- it fits observed mortality data well, especially for older ages,

- it is a stochastic generalization of the Gompertz law, since its expected value is exponentially increasing with time,

- not only it permits to compute survival probabilities in closed form but it allows to derive sensitivities to mortality forecast error in closed and simple form.

In order to price insurance products following standard risk-neutral valuation, we introduce an equivalent martingale measure $\mathbb{Q}$. We assume its existence and we refer the reader to Dahl and Møller (2006) for details about the properties of the involved change of measure. For simplicity, and given the difficulties of calibrating the risk premium in the absence of a well-developed mortality derivatives market, we make the (standard) assumption of absence of a risk premium for mortality, extensions to all constant risk premiums being straightforward. ${ }^{1}$ As a consequence, survival probabilities under the risk-neutral measure coincide with those under the historical one. Having selected an affine process for mortality intensity, we obtain the expression for survival probabilities in closed-form

$$
S_{x}(t, T)=\mathbb{E}^{\mathbb{Q}}\left[e^{-\int_{t}^{T} \lambda(u) d u} \mid \mathcal{F}_{t}\right]=e^{\alpha(T-t)+\beta(T-t) \lambda_{x}(t)} .
$$

\footnotetext{
${ }^{1}$ This assumption is justified by the impossibility of calibrating the market price of risk for mortality, while a liquid market for insurance derivatives has not developed yet.
} 
$\mathcal{F}_{t}$ denotes the filtration generated by $W_{x}^{\mathbb{P}}(t)$. The functions $\alpha(\cdot)$ and $\beta(\cdot)$ solve a system of Riccati differential equations (see f.i. Duffie et al. (2000)), such that

$$
\begin{aligned}
& \beta(t)=\frac{1}{a_{x}}\left(1-e^{a_{x} t}\right), \\
& \alpha(t)=\frac{\sigma_{x}^{2}}{a_{x}^{2}}\left(\frac{t}{2}-\frac{e^{a_{x} t}}{a_{x}}+\frac{e^{2 a_{x} t}}{4 a_{x}}+\frac{3}{4 a_{x}}\right) .
\end{aligned}
$$

\subsubsection{Interest-rate risk}

We describe the uncertainty surrounding the short rate and affecting the market valuation of liabilities using the standard and well-known Vasicek (1977) process. Under the usual risk-neutral measure $\mathbb{Q}$, equivalent to $\mathbb{P}$, short-rate dynamics is

$$
d r(t)=k(\theta-r(t)) d t+\sigma_{r} d W_{F}^{\mathbb{Q}}(t),
$$

where $r(0)=r_{0}>0$ and $k, \theta, \sigma_{r}>0$. We assume independence assumption between mortality and interest-rate risk. Hence, the Brownian motions $W_{F}$ and $W_{x}$ are independent for any $x$. It is well known that, since the process described by equation (2) is affine, a closed-form expression for bond prices is readily available:

$$
B(t, T)=X(t, T) e^{-Y(t, T) r(t)}
$$

where

$$
\begin{aligned}
& Y(t, T)=\frac{1}{k}\left(1-e^{-k(T-t)}\right), \text { and } \\
& X(t, T)=\exp \left[\left(\theta-\frac{\sigma_{r}^{2}}{2 k^{2}}\right)(Y(t, T)-T+t)-\frac{\sigma_{r}^{2}}{4 k} Y(t, T)^{2}\right] .
\end{aligned}
$$

We simulate the process under the physical measure. We assume a constant risk premium per unit of risk $\gamma$. The short rate under the historical measure takes thus the form

$$
d r(t)=k\left[\theta-\frac{\gamma \sigma_{r}}{k}-r(t)\right] d t+\sigma_{r} d W_{F}^{\mathbb{P}}(t),
$$


where $W_{F}^{\mathbb{P}}=d W_{F}^{\mathbb{Q}}+\gamma d t$ is a Brownian motion under the physical measure.

When we discretize the process for simulation purposes, at each $t_{i} \in \mathbb{I}$ we have

$$
r\left(t_{i}\right)=k\left[\theta-\frac{\gamma \sigma_{r}}{k}-r\left(t_{i-1}\right)\right] \Delta+\sigma_{r}\left[W_{F}^{\mathbb{P}}\left(t_{i-1}\right)-W_{F}^{\mathbb{P}}\left(t_{i-1}\right)\right]
$$

\subsubsection{Idiosyncratic risk}

Let us define with $\tau^{A}=\left\{\tau_{i}^{A}\right\}_{i=1}^{N_{A}}$ and $\tau^{B}=\left\{\tau_{i}^{B}\right\}_{i=1}^{N_{B}}$ the sets of lifetimes of the $N_{A}$ annuitants and $N_{D}$ death contracts policyholders which we assume are i.i.d. random variables. The counting processes $D_{A}(t)$ and $D_{D}(t)$, which count the number of deaths in the two portfolios can be defined as

$$
D_{A}(t)=\sum_{i=1}^{N_{A}} \mathbb{1}_{\left\{\tau_{i}^{A}<t\right\}} \text { and } D_{D}(t)=\sum_{i=1}^{N_{D}} \mathbb{1}_{\left\{\tau_{i}^{B}<t\right\}} \text {. }
$$

We assume that no premium is given to idiosyncratic risk, since it is diversified away in large portfolios.

\subsubsection{Fair-value reserving and liability portfolio value}

Given our choices for the stochastic mortality and interest-rate models, we now provide the fair-value reserves of death contracts and annuities written on a cohort $x$. Since we showed that closed-form expressions for bond prices and survival probabilities are available, and given the independence assumption between longevity and financial risks, we obtain the present value of annuties and death contracts in closed form. This feature entails a computational advantage with respect to discrete-time mortality models, for which annuity values have to be computed through numerical procedures. Fairvalue reserves are computed under the hypothesis that idiosyncratic risk is absent, i.e. that is diversified away. ${ }^{2}$ Given the results in Luciano et al. (2012), the fair-value of a whole-life annuity $A(x, R),\left(Z_{x}^{A}\right)$, is the expected present value of the future payments to the annuitant, discounted appropriately given the term structure of interest rates and survivorship

$$
Z_{x}^{A}\left(t_{i}\right)=R \sum_{\substack{t_{j} \in T_{A}^{O}(x, R), t_{j}>t_{i}, t_{j} \leq t_{\omega}}} B\left(t_{i}, t_{j}\right) S\left(t_{i}, t_{j}\right),
$$

\footnotetext{
${ }^{2}$ This assumption is harmless for large portfolios. In simulations, we include this source of randomness and evaluate its impact, by computing the solvency probability for different portfolio sizes.
} 
where $t_{\omega} \in \mathbb{I}$ is the time at which the individual reaches its terminal age, after which the survival probability is zero.

On the other hand, we assume that the payments associated with the death contract $D(x, Q, C)$ are due at the end of the year in which the death event occurred. It follows that the outflow associated to a death between to successive payment dates $t_{j-1}$ and $t_{j}$ occurs at $t_{j}$.

The market value of the obligation originated with the contract, i.e. its prospective reserve, $\left(Z_{x}^{D}\right)$, at $t_{i}$ is thus

$$
Z_{x}^{D}\left(t_{i}\right)=C \sum_{\substack{t_{j} \in T_{D}^{O}(x, Q, C), t_{j}>t_{i}, t_{j} \leq t_{0}+Q}} B\left(t_{i}, t_{j}\right)\left[S\left(t_{i}, t_{j-1}\right)-S\left(t_{i}, t_{j}\right)\right] .
$$

Luciano et al. (2012) defined the longevity risk factor as the difference between actual mortality at some future point in time and its model forecast at the time of evaluation, i.e. the forward mortality rate. They show that the first and second order sensitivities (Greeks) of death assurances with respect to this risk factor have opposite signs with respect to those of annuities. This consideration, well known in the actuarial practice, opens up the possibility of mitigating systematic longevity risk by appropriately mixing annuities and life insurance policies. However, the Greeks of these two types of policies with respect to the interest-rate risk factor - analogously defined as the difference between the future actual short-rate and the forward interest rate have the same sign. It is important not to neglect this aspect when hedging the fair-value of liabilities. The longevity risk present in a portfolio of annuities can be instantaneously neutralized by issuing death contracts, but additional interest-rate risk enters the portfolio in the process. Two options are available: managing interest rate risk on the bond market after having neutralized mortality risk or handling them simultaneously. In this last case, by combining insurance contracts and mortality derivatives or reinsurance appropriately, it is - at least in theory, if such products are available in the market - possible to avoid using bonds.

The value of the liabilities portfolio (L) is simply, at each point in time, the sum of the value of all the obligations the company has outstanding. For each $t_{i} \in \mathbb{I}$, this value is equal to the expected discounted value of future benefits due to policyholders, thus

$$
L\left(t_{i}\right)=\left(N_{A}-D_{A}\left(t_{i}\right)\right) Z_{A}\left(t_{i}\right)+\left(N_{D}-D_{D}\left(t_{i}\right)\right) Z_{D}\left(t_{i}\right)
$$

and can be computed in closed-form as discussed in the previous section. 


\section{$2.2 \quad$ Assets}

The insurance company has an initial capital available $A\left(t_{0}\right)$, which, without loss of generality, we assume to be equal to the (single) premiums received at $t_{0}$ when the policies are issued.

The investment opportunity set includes the money market account, which grows at the prevailing short interest-rate, the bond market, which we already described, and the stock market, in which equity risk is present. At each $t_{i}$ the fund invests a fraction $\delta_{M}\left(t_{i}\right)$ of its assets $A\left(t_{i}\right)$ in the stock market, $\delta_{B}\left(t_{i}\right)$ in the bond market and the remaining part in the money market account. Also at each $t_{i}$, the company pays out the benefits associated with the liabilities portfolio to policyholders and rebalances the investment strategy. Disinvestments from the asset side cover these outflows, creating a direct link between the asset side and the liability side. Being dependent on the net flows of the liability portfolio, assets become subject to both idiosyncratic and systematic longevity risk.

\subsubsection{Equity risk: investment in the stock market}

Investment in the stock market is risky. We assume that the insurance company can invest in one risky stock, whose dynamics, under the historical measure $\mathbb{P}$, follows a Geometric Brownian Motion

$$
\frac{d M(t)}{M(t)}=\mu d t+\sigma_{M} d W_{M}^{\mathbb{P}}(t),
$$

where $\mu>0$ is the drift and $\sigma_{M}>0$ is the diffusion coefficient of the process and $W_{M}^{\mathbb{P}}$ is a Brownian Motion under the $\mathbb{P}$ measure, independent by assumption of both $W_{x}^{\mathbb{P}}$ and $W_{F}^{\mathbb{P}}$. At the time of policy inception, $t_{0}$, a fraction $\delta_{M}\left(t_{0}\right)$ of the inital asset value $A\left(t_{0}\right)$ is invested in the stock market, hence $M\left(t_{0}\right)=\delta_{M}\left(t_{0}\right) A\left(t_{0}\right)$. When we introduce portfolio rebalancing, the value invested in the stock market follows the dynamics (6) between any two time points $t_{i-1}$ and $t_{i}^{-}$, where $t_{i}^{-}$denotes the instant right before rebalancing occurs. Hence, we have

$$
M\left(t_{i}^{-}\right)=M\left(t_{i-1}\right) \exp \left\{\left(\mu-\frac{\sigma_{M}^{2}}{2}\right) \Delta+\sigma_{M}\left[W_{M}^{\mathbb{P}}\left(t_{i}^{-}\right)-W_{M}^{\mathbb{P}}\left(t_{i-1}\right)\right]\right\},
$$

where $M\left(t_{i-1}\right)$ is the value invested in the stock market after rebalancing the portfolio at $t_{i-1}$. By continuity of the Brownian motion, $W_{M}^{\mathbb{P}}\left(t_{i}^{-}\right)=W_{M}^{\mathbb{P}}\left(t_{i}\right)$. 
Stock investment is not hedged and it is considered to represent the different asset allocation strategies of the fund. It is outside the scope of the present paper to account for this aspect. We leave to further extensions the interesting case in which equity risk affects the liabilities' side also, for instance when guaranteed or participating contracts are issued.

\subsubsection{Investment in the bond portfolio and in the money market account}

Apart from investing in the stock market, the insurance company can hold a portfolio of zero coupon bonds with maturity $T_{B}$. The initial investment in the bond portfolio is a fraction of initial capital available, i.e. $P(0)=$ $\delta_{B} A(0)$. From now on, we define our investment strategy at time $t_{i}$ as the pair $\left(\delta_{M}\left(t_{i}\right), \delta_{B}\left(t_{i}\right)\right)$. The number of bonds entering the bond portfolio at time $t_{0}$ is

$$
n_{B}\left(t_{0}\right)=P(0) / B\left(t_{0}, T_{B}\right),
$$

where the value of the bond at time $t_{0}$, and in general at any point in time $t_{i}$, $B\left(t_{i}, T_{k}\right)$, can be computed according to formula (3), given the current value of the short-rate process $r\left(t_{i}\right)$.

The total value of the bond portfolio, immediately prior to any rebalancing time $t_{i}>t_{0}$, is

$$
P\left(t_{i}^{-}\right)=n_{B}\left(t_{i-1}\right) B\left(t_{i}^{-}, T_{B}\right)
$$

where $n_{B}\left(t_{i-1}\right)$ represents the number of bonds in the portfolio at time $t_{i-1}$, after portfolio rebalancing at that time according to the chosen strategy $\left(\delta_{M}\left(t_{i-1}\right), \delta_{B}\left(t_{i-1}\right)\right)$. At any time $t_{i}$ the number of bonds in the portfolio is

$$
n_{B}\left(t_{i}\right)=P\left(t_{i}\right) / B\left(t_{i}, T_{B}\right),
$$

with $P\left(t_{i}\right)=\delta_{B}\left(t_{i}\right) A\left(t_{i}\right)$. The remaining fraction of the assets, (1$\left.\delta_{M}\left(t_{i}\right)-\delta_{B}\left(t_{i}\right)\right)$ is invested in the money market account, so that, at each time $t_{i}$ its value $V_{t_{i}}$ is equal to

$$
V\left(t_{i}\right)=\left(1-\delta_{M}\left(t_{i}\right)-\delta_{B}\left(t_{i}\right)\right) A\left(t_{i}\right) .
$$

The value of the money market account grows at the prevailing short interest rate. Hence, immediately prior to rebalancing, when the returns from investment in period $\Delta$ are computed, we have

$$
V\left(t_{i}^{-}\right)=V\left(t_{i-1}\right) e^{r_{t_{i-1}} \Delta} .
$$


In the numerical section, we also explore the case in which, instead of implementing a portfolio allocation strategy of the type $\left(\delta_{M}\left(t_{i}\right), \delta_{B}\left(t_{i}\right)\right)$, we Delta-hedge the portfolio according to Luciano et al. (2012). The Appendix summarizes the theory behind the strategy. At each $t_{i}$, we compute the number of bonds to hold in the portfolio $n_{B}\left(t_{i}\right)$ such that the exposure of the asset-liability portfolio with respect to the interest-rate risk factor is instantaneously nullified. As a consequence, the optimal amount invested in bonds at $t_{i}$ is $P\left(t_{i}\right)=n_{B}\left(t_{i}\right) B\left(t_{i}, T_{B}\right)$. If $P\left(t_{i}\right)<A\left(t_{i}\right)$ the strategy can be implemented properly, and the remaining amount $A\left(t_{i}\right)-P\left(t_{i}\right)$ is invested in the money market account. If $P\left(t_{i}\right) \geq A\left(t_{i}\right)$, the company does not have enough funds to buy the required number of bonds. It then implements a sub-optimal strategy, by setting $P\left(t_{i}\right)=A\left(t_{i}\right)$ and computing the number of bonds in the portfolio according to equation (7).

\subsubsection{Asset Value}

Finally, we are ready to include the outflows of the liability portfolio and to compute the value of assets at each point in time. Let us define the payments to policyholders $(O)$ at $t_{i}$ as

$$
\begin{aligned}
O\left(t_{i}\right)= & R\left(N_{A}-D_{A}\left(t_{i}\right)\right) \mathbb{1}_{\left\{t_{i} \in T_{A}^{O}(x, R)\right\}}+ \\
& C\left(D_{D}\left(t_{i}\right)-D_{D}\left(t_{j-1}\right)\right) \mathbb{1}_{\left\{t_{i}=t_{j} \in T_{D}^{O}(x, Q, C)\right\}}
\end{aligned}
$$

Here, $O\left(t_{i}\right)$ is the sum of the installments paid to annuitants which are still alive at $t_{i}$ and of the insured capital paid for death contract policyholders who died between the previous payment date and $t_{i}$, if $t_{i}$ is itself a payment date. If $t_{i}$ is not a payment date for any of the two contracts then $O\left(t_{i}\right)=0$.

In order to implement the selected investment strategy $\left(\delta_{M}\left(t_{i}\right), \delta_{B}\left(t_{i}\right)\right)$, we value the asset portfolio at $t_{i}^{-}$, sell it, and buy the assets again so as to implement our portfolio strategy at $t_{i}{ }^{3}$

The value of assets at time $t_{i}$ is the sum of the values of the stock market, the bond market and the money market accounts, net of payments to policyholders

$$
A\left(t_{i}\right)=M\left(t_{i}^{-}\right)+P\left(t_{i}^{-}\right)+V\left(t_{i}^{-}\right)-O\left(t_{i}\right) .
$$

Given this value, we re-balance the asset portfolio in order to implement the

\footnotetext{
${ }^{3}$ For simplicity, we assume that no transaction costs affect our rebalancing.
} 
asset allocation strategy at $t_{i}$

$$
\begin{aligned}
M\left(t_{i}\right) & =\delta_{M}\left(t_{i}\right) A\left(t_{i}\right), \\
P\left(t_{i}\right) & =\delta_{B}\left(t_{i}\right) A\left(t_{i}\right), \text { and } \\
V\left(t_{i}\right) & =\left(1-\delta_{M}\left(t_{i}\right)-\delta_{B}\left(t_{i}\right)\right) A\left(t_{i}\right) .
\end{aligned}
$$

\section{$3 \quad$ Numerical assessment of solvency - A calibrated application}

In this section we present a calibrated application which allows us to appraise the importance of systematic longevity risk in annuity portfolios and to assess the performance of natural hedging strategies. Natural hedging strategies can be readily implemented by insurance companies and, in the absence of a well developed mortality derivatives market, constitute a cheap and effective way of reducing longevity risk.

First, we discuss the quantities we evaluate in order to assess solvency, in the light of previous literature and insurance practice. Then, we describe data and calibration and we analyze our results.

\subsection{Solvency assessment}

The main goal behind assessing the solvency of an insurance company is to ascertain whether the company, at some future time horizon, will be able to meet its financial obligations. Having this in mind, we focus our analysis on the funding ratio $(F)$ of a portfolio, i.e. the ratio between asset and liability market values at a certain point in time $t_{i} \in \mathbb{I}$. We define

$$
F\left(t_{i}\right):=\frac{A\left(t_{i}\right)}{L\left(t_{i}\right)}
$$

Here, we assume that the portfolio is set up at time $t_{0}$, when the policies are sold at a single premium. Their premium is equal at least to their fair value or increased by a proportional safety loading $\eta$. For simplicity, no initial funds owned by the insurance company are assumed. Hence, at time $t_{0}$, the funding ratio is above or equal to one. The entire amount of assets at time $t_{0}, A\left(t_{0}\right)$, is invested according to the fixed proportion strategy $\left(\delta_{M}, \delta_{B}\right)$, in which $\delta_{M}\left(t_{i}\right)=\delta_{M}, \delta_{B}\left(t_{i}\right)=\delta_{B}$ for every $t_{i}$ or to the hedging strategy, as 
described in the previous section. The risk sources previously described affect both assets and liabilities, turning the funding ratio into a stochastic variable, whose key distributional characteristics we wish to capture at any relevant future point in time $t_{0}+T$. The quantity we want to assess is the probability that the insurer is solvent at maturity $T$, defined as the probability that the funding ratio is greater than or equal to one at the selected maturity, i.e. $\mathbb{P}[F(T) \geq 1] .{ }^{4}$ However, evaluating this probability alone is not sufficient to describe the risk profile of the insurance company. Relevant information is provided by the variability of funding ratio and by the characteristics of its distributions, such as its relevant percentiles. In our numerical section we thus focus on the coefficient of variation (CV) of funding ratio, defined as

$$
\mathrm{CV}\left[F\left(t_{i}\right)\right]:=\frac{\sqrt{\operatorname{Var}\left[F\left(t_{i}\right)\right]}}{\mathrm{E}\left[F\left(t_{i}\right)\right]} .
$$

Regulation as well as insurance practice (see Olivieri and Pitacco (2002) and Pitacco et al. (2009), for instance) place so-called solvency requirements on insurance portfolios. These requirements are constructed in terms of risk measures, which are based on the properties of the funding ratio distribution. The most popular requirement, which we consider, is of the type $\mathbb{P}[F(T) \geq$ $1]=\epsilon$, where $\epsilon$ is some prescribed probability level.

In our numerical analysis, we compute the smallest safety margin $\eta$ necessary to reach the required solvency target at the prescribed level of $\epsilon=99.5 \%$ for a given maturity $T$. Additionally, since tail-risk measures are very important, as they assess the expected losses in the worst-case scenario, we evaluate the conditional tail expectation $\mathrm{E}[F(T) \mid F(T)<Q(\epsilon)]$ having $\epsilon=0.5 \%$ and $2.5 \%$ where, by $Q$, the quantile function of the funding ratio is denoted.

\subsection{Setup and calibration}

We calibrate the mortality intensity and interest-rate processes to UK data at the end of year 2010. In particular, we consider contracts written on the generation of individuals born in 1945, having turned 65 within 2010. Table 1 reports our calibrated parameters. We calibrate the OU model by maximum

\footnotetext{
${ }^{4}$ Analogously, actuarial literature focuses on multi-period solvency, i.e. at the probability that the funding ratio is above one from any future point in time $t^{*}$, or at discrete dates, up to time $t^{*}+T, \mathbb{P}\left[\wedge_{t^{*}}^{t^{*}+T} F(t) \geq 1\right]$. In particular, this view is consistent with the prevailing guidelines to Own Risk Solvency Assessment (ORSA), which focus on a medium (3-5 years) rather than a short time horizon.
} 


\begin{tabular}{|c|c|c|c|c|c|}
\hline \multicolumn{6}{|c|}{ Base-case parameters } \\
\hline \multicolumn{2}{|c|}{$\begin{array}{l}\text { GBM } \\
\text { model }\end{array}$} & \multicolumn{2}{|c|}{$\begin{array}{c}\text { Stochastic mortality } \\
\text { model }\end{array}$} & \multicolumn{2}{|c|}{$\begin{array}{c}\text { Interest-rate model } \\
\text { model }\end{array}$} \\
\hline Parameter & Value & Parameter & Value & Parameter & Value \\
\hline$\mu$ & 0.053467 & $a_{x}$ & 0.072517 & $k$ & 0.233821 \\
\hline \multirow{4}{*}{$\sigma_{M}$} & 0.148889 & $\sigma_{x}$ & 0.000147 & $\theta$ & 0.030637 \\
\hline & & $\lambda(0)$ & 0.011891 & $\sigma_{r}$ & 0.009400 \\
\hline & & & & $r(0)$ & 0.007600 \\
\hline & & & & $\gamma$ & -0.573509 \\
\hline
\end{tabular}

Table 1: The table reports calibrated parameters for mortality, interest-rate and GBM models.

likelihood, using observed mortality rates from age 45 to age $65 .{ }^{5}$ The initial value $\lambda(0)$ is selected so that $\lambda(0)=-\ln p_{65}$, where $p_{65}$ denotes - as usual the survival rate for the cohort at age 65 , which represents the last observation available. Given the calibrated parameters, the probability of having a negative mortality intensity at any maturity up to $T=45$ is calculated and found negligible (at most in the order of magnitude of $10^{-200}$, cf. Luciano and Vigna (2008)). Forecasted average mortality rates are in line with projected tables published by national (e.g. ONS (2013)) and international institutions (UN, World Population Prospects UN (2014)). The diffusion parameter $\sigma_{r}$ of the Vasicek process is estimated using maximum likelihood from a monthly time series of short rates (source: OECD) from January 1978 to December 2010. The other parameters $(k, \theta$ and the risk premium $\gamma)$ are derived by fitting the observed term structure given UK government bonds at $31^{\text {st }}$ of December 2010, minimizing the rooted mean square error between observed and fitted prices. Stock market parameters are calibrated from a 20-year monthly time series of FTSE 100 returns from 1990 to 2010.

We consider two portfolios in run-off: a small portfolio, composed of $N_{A}=1000$ annuitants and a second one, large and thus well-diversified portfolio, composed of $N_{A}=50000$ annuitants. Each annuitant holds an $A(1945,1)$ policy, whose single premium, 16.08 , is paid at $t_{0}=2011$. For each experiment, we run 10000 simulations of the whole life of the insurance portfolio, until time $t_{\omega}=t_{0}+45=2056$. Diffusions are discretized at monthly intervals. Summarizing, at each time $t_{i}$, we

\footnotetext{
${ }^{5}$ Data were downloaded on $3^{\text {rd }}$ of November 2010 from Human Mortality Database (2010).
} 
1. determine the value of the short rate $r\left(t_{i}\right)$, mortality intensity $\lambda_{x}\left(t_{i}\right)$ and stock $M\left(t_{i}\right)$ by incrementally simulating the respective processes;

2. given the current $r\left(t_{i}\right)$, we obtain the term structure of interest rates;

3. given the actual mortality intensity, $\lambda_{x}\left(t_{i}\right)$, in order to obtain the number of annuitants still alive $\left(N_{A}\left(t_{i}\right)-D_{A}\left(t_{i}\right)\right)$, we simulate the number of deaths occurred in the portfolio in the appropriate time interval ${ }^{6}$ and we find the survival probability curve;

4. assess the current value of assets and the present value of liabilities;

5. rebalance the value invested in stock market and the number of bonds in the portfolio and implement the selected asset allocation strategy.

\subsection{Importance of systematic longevity risk and its hedging}

Traditional actuarial practice used deterministic methods to project the evolution of mortality. As a consequence, when insurance liabilities are evaluated at fair-value - as current regulation imposes in some countries - this approach would suggest that interest rate risk is the main source of uncertainty to manage. However, the unexpectedly high longevity improvements experienced in the last decades have threatened the solvency of annuity providers, pointing out clearly that assessing longevity risk should not be neglected. Our numerical analysis strongly supports this need, by analyzing the relative importance of the risk sources which affect an insurance portfolio.

Figure 1 shows the percentiles of the simulated annuitant survival rates. The upper panel reports the figures in case of idiosyncratic risk (I) only is present. This case is obtained by using the deterministic counterpart of the OU model (Equation (1)), where $\sigma_{x}$ is null and we find calibrated parameter $a_{x}=0.075941$. Interest-rate variability is nullified by considering the same simulated short rate path for all the simulations. Idiosyncratic risk is almost entirely diversified away in the large portfolio, as the percentiles in the subfigure (b) are very close to each other. The distribution of policyholders' survivorship is instead much more volatile in the small portfolio as seen in

\footnotetext{
${ }^{6}$ When the life insurance portfolio is introduced, we simulate the number of deaths occurred in it, $\left(D_{D}\left(t_{i}\right)-D_{D}\left(t_{i-1}\right)\right.$, analogously to what we do for the annuity portfolio.
} 


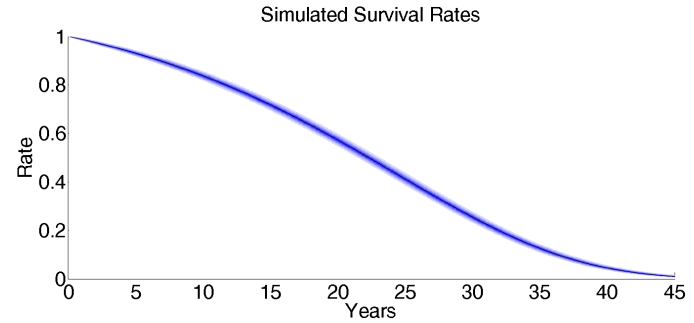

(a) $N_{A}=1000,(\mathrm{I})$

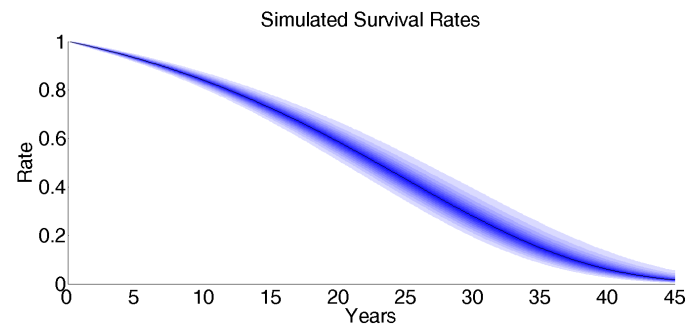

(c) $N_{A}=1000,(\mathrm{I})+(\mathrm{S})$

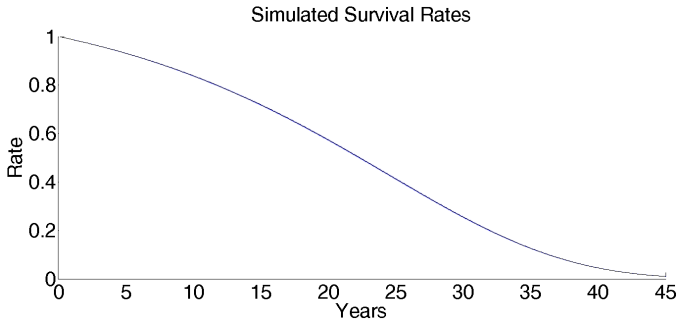

(b) $N_{A}=50000,(\mathrm{I})$

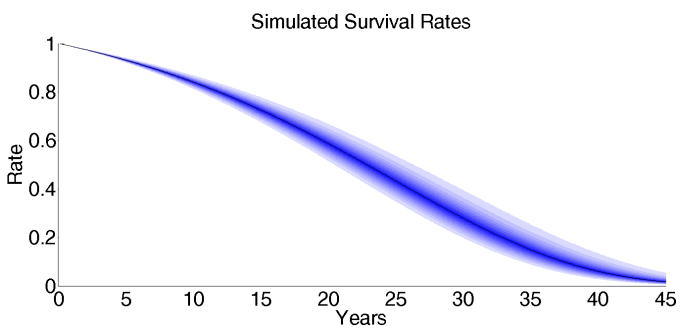

(d) $N_{A}=50000,(\mathrm{I})+(\mathrm{S})$

Figure 1: The figure shows, at 5 percent intervals, 5 to 95 percentiles of simulated 10000 paths of annuitant survival rates for the 1000 annuity contracts portfolio on the left hand side and, for 50000 annuity contracts portfolio on the right hand side, in the presence of one or several risk sources, such as idiosyncratic risk (I), interest-rate risk (IR) and systematic longevity risk $(\mathrm{S})$.

subfigure (a). When, having canceled out the variability due interest-rates as above, in addition to idiosyncratic risk, the systematic longevity risk (S) is accounted for, both portfolios are substantially affected. The coefficient of variation of the distribution of the number of policyholders alive belonging to the initial portfolio is remarkable and growing with time (see Table 2), reflecting the higher level of uncertainty which surrounds predictions more distant in time. The small portfolio experiences larger variability in survivorship at all horizons. It is clear that taking into account the stochasticity in mortality rates due to unexpected changes in survivorship of individuals, i.e. accounting for systematic longevity risk, is crucial to assess the risk profile of an annuity provider.

Figure 2 shows, for both portfolios, the simulated market value of liabilities given the interactions of the different risk sources. The comparison of subfigure (c) and (e) (or, analogously, of (d) and (f)) in the panel allows us to identify interest rate risk (IR) as the major culprit for the variability 


\begin{tabular}{lcc}
\multicolumn{3}{c}{$\mathrm{CV}\left[N_{A}(T)\right]$} \\
\hline & 1000 & 50000 \\
& Annuity & Annuity \\
$T$ & contracts & contracts \\
\hline 1 & 0.003540 & 0.000668 \\
5 & 0.010619 & 0.006184 \\
10 & 0.024422 & 0.019911 \\
20 & 0.083257 & 0.078452 \\
30 & 0.218971 & 0.210472 \\
40 & 0.535583 & 0.513117 \\
\hline
\end{tabular}

Table 2: This table reports the simulated value of the CV of the number of annuitants alive at different horizons $\mathrm{T}=1,5,10,20,30,40$.

in earlier years, while systemic longevity risk (S) becomes more and more relevant as the time horizon lengthens.

Table 3 reports the coefficient of variation of the funding ratio and asset and liability values at different maturities $T$ ( $T=1,5,10$ and 20 years). Assets are entirely invested in the money market account, which grows at the realized short rate. Idiosyncratic risk is negligible in the large portfolio, as the (I) row of the table highlights. While variability due to interest rates is the most important risk source for the uncertainty in the funding ratio, because it affects both the asset and the liabilities' sides, systematic longevity risk has a substantial impact, almost independent of portfolio size. This is due to the mean-reverting property of the Vasicek process used to simulate interest-rates and to the non-mean reverting behaviour of the longevity risk model. The CV of liabilities, as the time horizon lengthens, becomes higher when $(\mathrm{I})+(\mathrm{S})$ are present, with respect to the $(\mathrm{I})+(\mathrm{IR})$. For instance, when $T=10$ years, for the well-diversified portfolio it is 0.086984 in the $(\mathrm{I})+(\mathrm{S})$ case and 0.042747 in the (I)+(IR) case. As payments to annuitants deplete asset value, the CV of assets in the long run is affected by systematic longevity risk as well, but to a lesser extent. In fact, the CV of the assets is higher in the $(\mathrm{I})+(\mathrm{S})$ case than in the $(\mathrm{I})$ only case, even in the large portfolio.

The importance of considering demographic systematic uncertainty, together with usual financial risks, is crucial for the solvency analysis of annuity portfolios: neglecting to cover against unexpected longevity improvements, together with interest rate changes, can be detrimental. This consideration supports the growing attention towards the development of a mortality derivatives' market and to reinsurance deals. In the next sections we explore, 


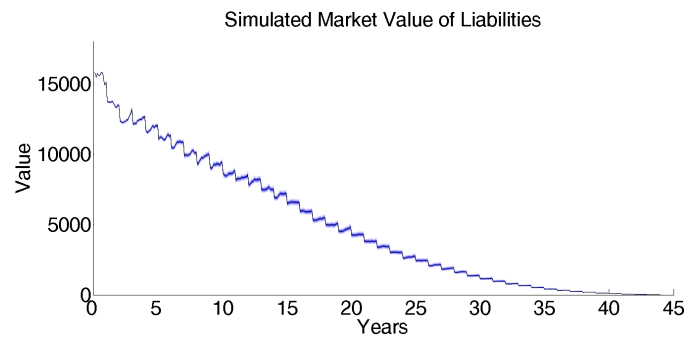

(a) $N_{A}=1000,(\mathrm{I})$

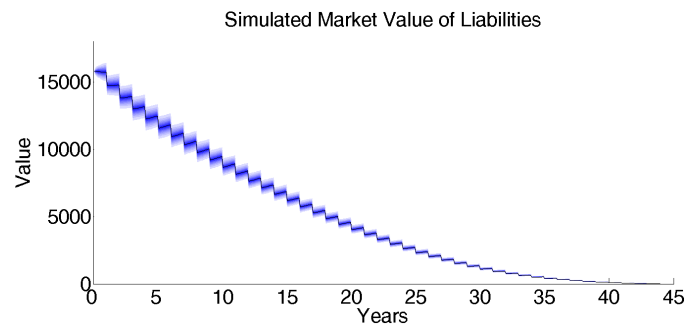

(c) $N_{A}=1000,(\mathrm{I})+(\mathrm{IR})$

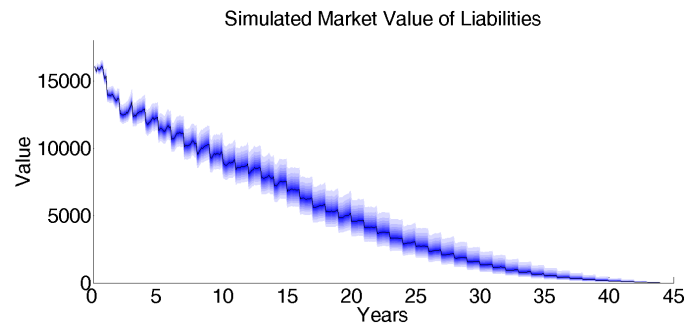

(e) $N_{A}=1000,(\mathrm{I})+(\mathrm{S})$

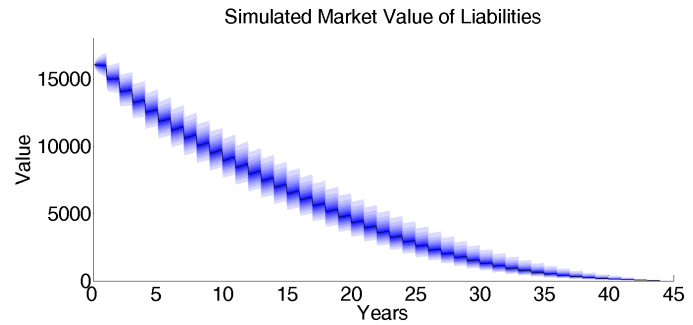

(g) $N_{A}=1000,(\mathrm{I})+(\mathrm{IR})+(\mathrm{S})$

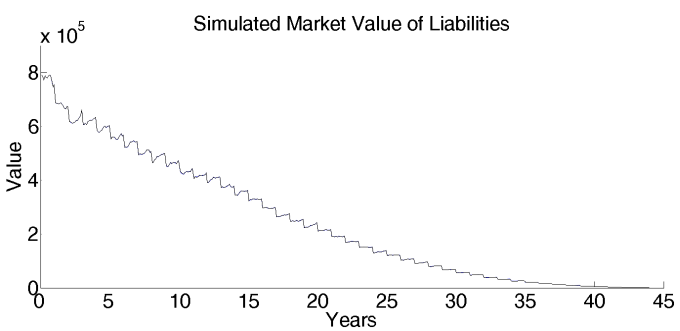

(b) $N_{A}=50000,(\mathrm{I})$

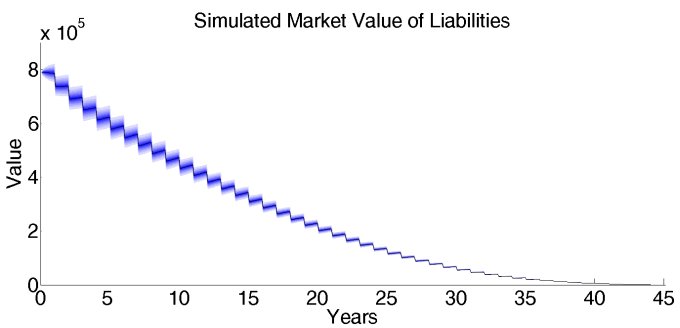

(d) $N_{A}=50000,(\mathrm{I})+(\mathrm{IR})$

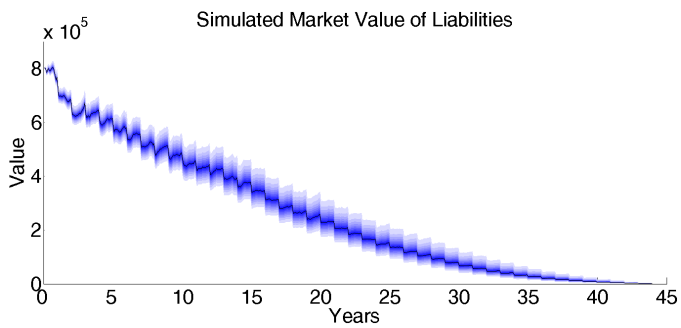

(f) $N_{A}=50000,(\mathrm{I})+(\mathrm{S})$

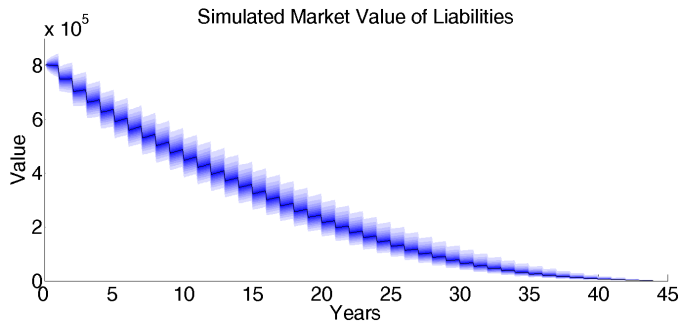

(h) $N_{A}=50000,(\mathrm{I})+(\mathrm{IR})+(\mathrm{S})$

Figure 2: The figure shows, at 5 percent intervals, 5 to 95 percentiles of 10000 simulated paths of market value of liabilities for the 1000 annuity contracts portfolio on the left hand side and, for 50000 annuity contracts portfolio on the right hand side, in the presence of one or several risk sources, such as idiosyncratic risk (I), interest-rate risk (IR) and systematic longevity risk $(\mathrm{S})$. 
CV of Funding Ratio, Assets, and Liabilities, given different risk sources

\begin{tabular}{|c|c|c|c|c|c|c|c|}
\hline & \multicolumn{2}{|c|}{$\mathrm{CV}[F(T)]$} & \multicolumn{2}{|c|}{$\mathrm{CV}[A(T)]$} & \multicolumn{2}{|c|}{$\mathrm{CV}[L(T)]$} \\
\hline & & 1000 & 50000 & 1000 & 50000 & 1000 & 50000 \\
\hline \multirow{4}{*}{$\mathrm{T}=1$} & (I) & 0.003784 & 0.000531 & 0.000228 & 0.000032 & 0.003551 & 0.000499 \\
\hline & $(\mathrm{I})+(\mathrm{IR})$ & 0.032710 & 0.032624 & 0.004979 & 0.005012 & 0.028526 & 0.028441 \\
\hline & $(\mathrm{I})+(\mathrm{S})$ & 0.022843 & 0.022466 & 0.000230 & 0.000043 & 0.022828 & 0.022502 \\
\hline & $(\mathrm{I})+(\mathrm{IR})+(\mathrm{S})$ & 0.040062 & 0.039845 & 0.004972 & 0.004976 & 0.036787 & 0.036522 \\
\hline \multirow{4}{*}{$\mathrm{T}=5$} & (I) & 0.010295 & 0.001488 & 0.001913 & 0.000274 & 0.008558 & 0.001240 \\
\hline & $(\mathrm{I})+(\mathrm{IR})$ & 0.085521 & 0.083208 & 0.048780 & 0.047922 & 0.043739 & 0.042476 \\
\hline & $(\mathrm{I})+(\mathrm{S})$ & 0.054923 & 0.053993 & 0.002146 & 0.001002 & 0.054310 & 0.053697 \\
\hline & $(\mathrm{I})+(\mathrm{IR})+(\mathrm{S})$ & 0.100478 & 0.100297 & 0.047859 & 0.048275 & 0.069836 & 0.069103 \\
\hline \multirow{4}{*}{$\mathrm{T}=10$} & (I) & 0.018978 & 0.002726 & 0.005758 & 0.000828 & 0.013931 & 0.002005 \\
\hline & $(\mathrm{I})+(\mathrm{IR})$ & 0.148878 & 0.145462 & 0.120786 & 0.118226 & 0.045109 & 0.042747 \\
\hline & $(\mathrm{I})+(\mathrm{S})$ & 0.091976 & 0.090828 & 0.008103 & 0.005738 & 0.087223 & 0.086984 \\
\hline & $(\mathrm{I})+(\mathrm{IR})+(\mathrm{S})$ & 0.172718 & 0.171610 & 0.118136 & 0.118459 & 0.098405 & 0.096691 \\
\hline \multirow{4}{*}{$\mathrm{T}=20$} & (I) & 0.043246 & 0.006086 & 0.018891 & 0.002693 & 0.027530 & 0.003872 \\
\hline & $(\mathrm{I})+(\mathrm{IR})$ & 0.313644 & 0.306349 & 0.298028 & 0.294146 & 0.047287 & 0.038747 \\
\hline & $(\mathrm{I})+(\mathrm{S})$ & 0.211739 & 0.207118 & 0.041760 & 0.037465 & 0.176827 & 0.175453 \\
\hline & $(\mathrm{I})+(\mathrm{IR})+(\mathrm{S})$ & 0.383859 & 0.380109 & 0.301916 & 0.300119 & 0.182345 & 0.178407 \\
\hline
\end{tabular}

Table 3: The table reports the coefficient of variation of funding ratio given 10000 simulated paths of funding ratio for the 1000 annuity contracts and 50000 annuity contracts portfolios, at different time horizons $T(T=1,5,10$ and 20) and in the presence of one or several risk sources, such as idiosyncratic risk (I), interest-rate risk (IR) and systematic longevity risk $(\mathrm{S})$.

through our numerical analysis, the effectiveness of natural hedging strategies of longevity risk, when different asset allocation strategies are implemented by the fund.

\subsection{Asset allocation strategies and solvency under systematic longevity risk}

We identify four fixed proportion portfolio strategies, which represent different risk profiles of annuity providers:

1. Dynamic financial Delta-hedging strategy ('DFDH'),

2. $\delta_{B}=80 \%, \delta_{M}=20 \%(' 80 \%-20 \%$ '),

3. $\delta_{B}=50 \%, \delta_{M}=50 \%(' 50 \%-50 \%$ '), 
4. $\delta_{B}=20 \%, \delta_{M}=80 \%$ ('20\%-80\%').

Strategy 'DFDH' represents a dynamic financial Delta-hedging strategy accomplished using bonds. The bond portfolio is entirely invested in a 12year bond, whose maturity matches the initial (standard) duration of the annuity portfolio. The strategy, whose implementation - which we describe in details in the Appendix - follows Jarrow and Turnbull (1994) and Luciano et al. (2012), is rebalanced at monthly intervals. ${ }^{7}$ The other three strategies mix investment in the equity and in the bond market. Strategy ' $50 \%-50 \%$ ' is close to the average asset allocation choices of a pension fund (see for instance Tower-Watson's report, 2013), while Strategies ' $80 \%-20 \%$ ' and '20\% - 80\%' constitute a less and more risky alternative, respectively. Longevity risk is not hedged in these strategies.

Following the analysis in Hari et al. (2008), Table 4 compares the simulated coefficient of variation, the 0.5 and 2.5 percentiles and the expected shortfall at $T=1$ and $T=5$ of the funding ratio, obtained implementing the four different strategies. All risk sources (idiosyncratic and systematic longevity risk, interest rate risk and equity risk) are taken into account in our simulations.

The solvency probability reported in the table seems to have a counterintuitive behaviour: the less risky strategy is associated to the lowest solvency probability. However, this measure does not allow us to appreciate the cost of underfunding when this happens or to take into account the dispersion around the distribution of the funding ratio. Looking more closely at the CV and at the percentiles of the funding ratio is more informative. For instance, despite having the lowest underfunding probability (62.8\% 1-year solvency probability), there is $0.5 \%$ probability that a 50000 annuitants fund which implements strategy '20\% - 80\%' experiences around $25.2 \%$ underfunding at a 1-year horizon. The dispersion of the funding ratio distribution, measured by the $\mathrm{CV}$, indeed increases with the riskiness of the strategy. The percentiles of the distribution of the funding ratio are lower the riskier the strategy. Interest-rate risk hedging is effective in improving the risk profile of the fund, as the percentiles and expected shortfalls are remarkably lower for the Delta-hedging strategy 'DFDH'.

\footnotetext{
${ }^{7}$ If current available funds are insufficient to buy the number of bonds required by the strategy, the fund invests its entire asset portfolio in bonds. The resources left after bond purchase are invested in the money market account.
} 
Funding ratio distribution characteristics without longevity risk hedging

\begin{tabular}{|c|c|c|c|c|c|c|c|}
\hline & Strategy & $\mathrm{CV}[F(T)]$ & $\mathrm{P}[F(T)>1]$ & $\mathrm{Q}(0.5 \%)$ & $\mathrm{Q}(2.5 \%)$ & $\begin{array}{c}\mathrm{E}[F(T) \mid F(T) \\
<Q(0.5 \%)]\end{array}$ & $\begin{array}{c}\mathrm{E}[F(T) \mid F(T) \\
<Q(2.5 \%)]\end{array}$ \\
\hline \multicolumn{8}{|c|}{1000 Annuity contracts } \\
\hline \multirow{4}{*}{$\mathrm{T}=1$} & DFDH & 0.023552 & 0.495100 & 0.938682 & 0.953727 & 0.930039 & 0.944391 \\
\hline & $80 \%-20 \%$ & 0.038811 & 0.586100 & 0.911820 & 0.933889 & 0.898730 & 0.919767 \\
\hline & $50 \%-50 \%$ & 0.082333 & 0.615600 & 0.827869 & 0.873971 & 0.807362 & 0.847376 \\
\hline & $20 \%-80 \%$ & 0.129290 & 0.617500 & 0.743512 & 0.807546 & 0.713805 & 0.770778 \\
\hline \multirow{4}{*}{$\mathrm{T}=5$} & DFDH & 0.059841 & 0.495300 & 0.846834 & 0.881623 & 0.827441 & 0.859243 \\
\hline & $80 \%-20 \%$ & 0.100332 & 0.616900 & 0.794073 & 0.846932 & 0.770391 & 0.814338 \\
\hline & $50 \%-50 \%$ & 0.213177 & 0.694500 & 0.631737 & 0.731899 & 0.589994 & 0.670200 \\
\hline & $20 \%-80 \%$ & 0.333861 & 0.698500 & 0.475560 & 0.603505 & 0.420159 & 0.525711 \\
\hline \multicolumn{8}{|c|}{50000 Annuity contracts } \\
\hline \multirow{4}{*}{$\mathrm{T}=1$} & DFDH & 0.023110 & 0.496000 & 0.938614 & 0.953876 & 0.930262 & 0.944197 \\
\hline & $80 \%-20 \%$ & 0.038636 & 0.590000 & 0.909322 & 0.935646 & 0.899860 & 0.920804 \\
\hline & $50 \%-50 \%$ & 0.082384 & 0.626700 & 0.830746 & 0.872709 & 0.812330 & 0.846292 \\
\hline & $20 \%-80 \%$ & 0.129487 & 0.628000 & 0.747969 & 0.807902 & 0.721785 & 0.769273 \\
\hline \multirow{4}{*}{$\mathrm{T}=5$} & DFDH & 0.058462 & 0.495200 & 0.847617 & 0.884900 & 0.825277 & 0.860014 \\
\hline & $80 \%-20 \%$ & 0.100502 & 0.624300 & 0.787175 & 0.847805 & 0.763071 & 0.810992 \\
\hline & $50 \%-50 \%$ & 0.214939 & 0.698200 & 0.619312 & 0.727778 & 0.578519 & 0.664196 \\
\hline & $20 \%-80 \%$ & 0.336763 & 0.699400 & 0.470402 & 0.598981 & 0.411566 & 0.519145 \\
\hline
\end{tabular}

Table 4: The table reports the coefficient of variation of funding ratio, solvency probability, the $0.5 \%$-quantile, the $2.5 \%$-quantile, and the expected shortfall for these quantiles given 10000 simulated paths of the funding ratio for the 1000 annuity contracts and 50000 annuity contracts portfolio, at different time horizons $T(T=1,5,10$ and 20$)$.

In order to quantify in a more appropriate way the risk profile of the fund, in Table 5 we report the initial safety loading $\eta$ required to reach a 1-year solvency probability of $99.5 \% .^{8}$ The table allows to appreciate, for each strategy, the "risk premium" that the fund has to charge to its policyholders at policy inception in order to reach the 1-year solvency target. strategy 'DFDH', which hedges interest-rate risk, allows the fund to charge the lowest premium, 6\%. The presence of idiosyncratic risk generates differences between the small and the large portfolios only when implementing the riskier strategies ' $50 \%-50 \%$ ' and '20\% - 80\%', in which the 50000 (10000) annuitants fund can reach the solvency target with a $18.9 \%(19.3 \%)$ and $31 \%$ $(31.8 \%)$ safety loading respectively.

\footnotetext{
${ }^{8}$ The choice of this threshold is in line with current Solvency II standard prescriptions.
} 


\begin{tabular}{|c|c|c|}
\hline \multicolumn{3}{|c|}{$\begin{array}{l}\text { Safety loading required to reach } \\
\text { 1-year } 99.5 \% \text { solvency probability } \\
\text { (Systemic longevity risk not hedged) }\end{array}$} \\
\hline Strategy & $\begin{array}{c}1000 \\
\text { Annuitants } \\
\text { contracts } \\
\end{array}$ & $\begin{array}{c}50000 \\
\text { Annuitants } \\
\text { contracts }\end{array}$ \\
\hline DFDH & $6.00 \%$ & $6.10 \%$ \\
\hline $80 \%-20 \%$ & $8.80 \%$ & $8.80 \%$ \\
\hline $50 \%-50 \%$ & $19.30 \%$ & $18.90 \%$ \\
\hline $20 \%-80 \%$ & $31.80 \%$ & $31.00 \%$ \\
\hline
\end{tabular}

Table 5: The table shows the safety loading required to reach 1-year $99.5 \%$ solvency probability given 10000 simulated paths of the market values of assets and liabilities for the 1000 annuity contracts and 50000 annuity contracts portfolio.

\subsection{Hedging strategies and effectiveness}

As a market for mortality derivatives is still in the making, we investigate the systematic longevity risk hedging potential of the liability portfolio mix. We analyze the effect of natural systematic longevity risk immunization techniques, whose design and performance on an insurance liability portfolio have been addressed in Luciano et al. (2012). Here, we extend the analysis of the effectiveness of such strategies in a context in which the asset side and the liabilities' side interact. Indeed, evaluating the effects of natural hedging on the funding ratio and on solvency probability is not an easy task, since the liability composition affects the asset through the payments made to policyholders. We then explore, via simulations, how the mitigation of systematic longevity risk, obtained by introducing life insurance policies in the portfolio of the insurer, along with the annuities, affects the solvency profile of the fund. We determine the size of the life insurance portfolio by applying the Delta-hedging technique in Luciano et al. (2012), using 10-year death contracts written on the same generation of the annuitants ${ }^{9} D(1945,10,100)$ to cover the annuity. The initial value of the policy is 14.34 . The number $N_{D}$ of policies in the portfolio is $40.3 \%$ the initial number of annuities sold by the company, i.e. 403 for the small portfolio, 20150 for the large portfolio. The

\footnotetext{
${ }^{9}$ It is indeed possible to consider life insurance policies written on different generations, introducing basis risk in the analysis. Given the high correlation between mortality intensities of different generations, considering basis risk is expected to have a very small impact in the effectiveness of the natural hedging strategy, and we thus leave this aspect aside.
} 
hedging is static, as the size of the life insurance portfolio is not rebalanced in time, but it simply evolves according to its death occurrences until all policies expire.

Funding ratio distribution characteristics, with natural hedging of longevity risk

\begin{tabular}{|c|c|c|c|c|c|c|c|}
\hline & Strategy & $\mathrm{CV}[F(T)]$ & $\mathrm{P}[F(T)>1]$ & $\mathrm{Q}(0.5 \%)$ & $\mathrm{Q}(0.5 \%)$ & $\begin{array}{c}\mathrm{E}[F(T) \mid F(T) \\
<Q(0.5 \%)]\end{array}$ & $\begin{array}{c}\mathrm{E}[F(T) \mid F(T) \\
<Q(2.5 \%)]\end{array}$ \\
\hline \multicolumn{8}{|c|}{1000 Annuity contracts } \\
\hline \multirow{4}{*}{$\mathrm{T}=1$} & DFDH & 0.009884 & 0.507300 & 0.969943 & 0.978360 & 0.965182 & 0.973382 \\
\hline & $80 \%-20 \%$ & 0.033741 & 0.586400 & 0.922008 & 0.941991 & 0.913133 & 0.930752 \\
\hline & $50 \%-50 \%$ & 0.081582 & 0.617600 & 0.826905 & 0.874834 & 0.807724 & 0.847895 \\
\hline & $20 \%-80 \%$ & 0.130576 & 0.618500 & 0.739491 & 0.807169 & 0.708354 & 0.767070 \\
\hline \multirow{4}{*}{$\mathrm{T}=5$} & DFDH & 0.034794 & 0.479300 & 0.904830 & 0.927861 & 0.891492 & 0.913854 \\
\hline & $80 \%-20 \%$ & 0.095655 & 0.598500 & 0.791644 & 0.843617 & 0.765211 & 0.813314 \\
\hline & $50 \%-50 \%$ & 0.220350 & 0.687500 & 0.599198 & 0.712232 & 0.555568 & 0.645423 \\
\hline & $20 \%-80 \%$ & 0.349063 & 0.688000 & 0.427155 & 0.577514 & 0.373565 & 0.489791 \\
\hline \multicolumn{8}{|c|}{50000 Annuity contracts } \\
\hline \multirow{4}{*}{$\mathrm{T}=1$} & $\mathrm{DFDH}$ & 0.001579 & 0.398500 & 0.994812 & 0.996226 & 0.993762 & 0.995320 \\
\hline & $80 \%-20 \%$ & 0.032462 & 0.593600 & 0.928435 & 0.945782 & 0.918365 & 0.935375 \\
\hline & $50 \%-50 \%$ & 0.081455 & 0.627600 & 0.835064 & 0.876366 & 0.813334 & 0.850222 \\
\hline & $20 \%-80 \%$ & 0.131007 & 0.628700 & 0.747245 & 0.807752 & 0.715980 & 0.769236 \\
\hline \multirow{4}{*}{$\mathrm{T}=5$} & DFDH & 0.008224 & 0.398500 & 0.968491 & 0.978490 & 0.962982 & 0.972409 \\
\hline & $80 \%-20 \%$ & 0.089565 & 0.610400 & 0.808106 & 0.857959 & 0.784719 & 0.827303 \\
\hline & $50 \%-50 \%$ & 0.217784 & 0.684100 & 0.608442 & 0.709971 & 0.566042 & 0.650565 \\
\hline & $20 \%-80 \%$ & 0.347254 & 0.688300 & 0.437319 & 0.571582 & 0.382462 & 0.492290 \\
\hline
\end{tabular}

Table 6: The table reports, in case of natural hedging, the coefficient of variation of funding ratio, solvency probability, the $0.5 \%$-quantile, the $2.5 \%$-quantile, and the expected shortfall for these quantiles given 10000 simulated paths of funding ratio for the 1000 annuity contracts and 50000 annuity contracts portfolio, at different time horizons $T$ $(T=1,5)$.

Table 6 reports the simulated coefficient of variation, the 0.5 and 2.5 percentiles and the expected shortfall at $T=1$ and $T=5$ of the funding ratio, obtained implementing the four different asset allocation strategies, when natural hedging is in place. It is evident that the Delta hedging strategy, which provides coverage against both interest-rate risk and systematic longevity risk, largely outperforms the others in terms of CV reduction and tail risk mitigation. In the large portfolio, the funding ratio ratio $\mathrm{CV}$ at $T=1$ is as small as 0.0016, while the less risky of the other strategies (2) 


\begin{tabular}{ccc}
\multicolumn{3}{l}{$\begin{array}{l}\text { Safety loading required to reach } \\
\text { 1-year } \\
\text { 99.5\% }\end{array}$ solvency probability } \\
(Systemic longevity & risk hedged) \\
\hline \multirow{2}{*}{ Strategy } & $\begin{array}{c}1000 \\
\text { Annuity } \\
\text { contracts }\end{array}$ & $\begin{array}{c}50000 \\
\text { Annuity } \\
\text { contracts }\end{array}$ \\
\hline DFDH & $2.70 \%$ & $0.50 \%$ \\
$80 \%-20 \%$ & $7.70 \%$ & $7.20 \%$ \\
$50 \%-50 \%$ & $19.10 \%$ & $18.10 \%$ \\
$20 \%-80 \%$ & $31.80 \%$ & $30.80 \%$ \\
\hline
\end{tabular}

Table 7: The table shows, in case of natural hedging, the safety loading required to reach 1-year $99.5 \%$ solvency probability given 10000 simulated paths of the market values of assets and liabilities for the 1000 annuity contracts and 50000 annuity contracts portfolio.

presents a $\mathrm{CV}$ which is 20 times bigger. In the worst-case scenario $(0.5 \%$ percentile) the expected underfunding at one-year (measured by the conditional expectation below the 0.5 percentile) is $0.6 \%$ only.

The presence of life insurance policies makes the impact of idiosyncratic risk more relevant. Comparing the results in Table 4 and Table 6 allows us to appreciate the impact of natural hedging on the funding ratio distribution. Contrary to Table 4, now the difference in risk profiles between the small and large portfolio can be appreciated for all strategies and time horizons.

When systematic longevity risk is hedged, strategy 'DFDH' improves all figures remarkably, for both portfolio sizes and time horizons. The only exception is Solvency probability, to which the previous considerations apply. For the other strategies, in which interest-rate risk is not hedged, natural hedge can worsen the risk position of the insurer. This happens because the introduction of the life insurance portfolio mitigates longevity risk on one side, but introduces additional financial risk on the other, when liabilities are evaluated at market value. Hence, when natural hedge is in place, quantiles and tail conditional expectations are higher for strategy ' $80 \%-20 \%$ ' (whose initial asset allocation is closest to that of strategy 'DFDH'), while these quantities lower for strategies ' $50 \%-50 \%$ ' and '20\% - 80\%'. However, Table 7 shows that, even in these cases, the safety loading required to reach the 1-year $99.5 \%$ solvency target is lower with natural hedging than in the no hedging case for all strategies and sizes. The reduction in the required loading with respect to the no longevity risk hedging case is striking in particular for strategy 'DFDH': $2.7 \%$ and $0.5 \%$ in the small and large portfolio respectively 
Bankruptcy probability

\begin{tabular}{|c|c|c|c|c|c|}
\hline & \multirow[b]{2}{*}{ Strategy } & \multicolumn{2}{|c|}{ No Natural Hedging } & \multicolumn{2}{|c|}{ Natural Hedging } \\
\hline & & $\begin{array}{c}1000 \\
\text { Annuity } \\
\text { contracts }\end{array}$ & $\begin{array}{c}50000 \\
\text { Annuity } \\
\text { contracts }\end{array}$ & $\begin{array}{c}1000 \\
\text { Annuity } \\
\text { contracts }\end{array}$ & $\begin{array}{c}50000 \\
\text { Annuity } \\
\text { contracts }\end{array}$ \\
\hline \multirow{4}{*}{$\mathrm{T}=10$} & DFDH & 0.0000 & 0.0000 & 0.0000 & 0.0000 \\
\hline & $80 \%-20 \%$ & 0.0000 & 0.0000 & 0.0000 & 0.0000 \\
\hline & $50 \%-50 \%$ & 0.0000 & 0.0000 & 0.0013 & 0.0009 \\
\hline & $20 \%-80 \%$ & 0.0008 & 0.0006 & 0.0145 & 0.0135 \\
\hline \multirow{4}{*}{$\mathrm{T}=20$} & DFDH & 0.0000 & 0.0000 & 0.0035 & 0.0000 \\
\hline & $80 \%-20 \%$ & 0.0075 & 0.0082 & 0.0466 & 0.0334 \\
\hline & $50 \%-50 \%$ & 0.0694 & 0.0701 & 0.1172 & 0.1101 \\
\hline & $20 \%-80 \%$ & 0.1335 & 0.1276 & 0.1717 & 0.1648 \\
\hline \multirow{4}{*}{$\mathrm{T}=30$} & DFDH & 0.3119 & 0.3072 & 0.3228 & 0.0785 \\
\hline & $80 \%-20 \%$ & 0.3033 & 0.2927 & 0.3533 & 0.3405 \\
\hline & $50 \%-50 \%$ & 0.2517 & 0.2436 & 0.2704 & 0.2672 \\
\hline & $20 \%-80 \%$ & 0.2692 & 0.2662 & 0.2819 & 0.2796 \\
\hline
\end{tabular}

Table 8: The table reports, in absence and presence of natural hedging, bankruptcy probability given 10000 simulated bankruptcy paths for the 1000 annuity contracts and 50000 annuity contracts portfolio, at different time horizons $T(T=1,5,10$ and 20$)$, and in the presence of idiosyncratic risk, interest-rate risk and systematic longevity risk.

in Table 7 compared to $6 \%$ and $6.1 \%$ of in Table 5 . In conclusion, having fixed the $99.5 \%$ 1-year solvency target, natural hedging of the portfolio allows the policyholder to charge its annuitants with a lower premium.

We conclude with a further indication of the importance of accounting properly for risk sources when assessing solvency and the effectiveness of hedging strategies. Table 8 and Table 9 help us understand the long term risks of insolvency of the portfolios and their related costs. First, we analyze bankruptcy probabilities up to 30 years. Insolvency likelihood is always higher in the small portfolio, due to the effect of idiosyncratic risk. Natural hedging reduces the probability of insolvency in the large portfolio when the 'DFDH' strategy is implemented. Our analysis shows that natural hedging (which is implemented statically and not rebalanced) can raise slightly the bankruptcy probability of the portfolio when interest-rate risk is not managed properly, especially at longer horizon and in small portfolios. This last effect is due to the additional idiosyncratic risk introduced along with the life insurance portfolio. The expected loss given default, reported in Table 


\begin{tabular}{cccccc}
\multicolumn{3}{c}{$\begin{array}{c}\text { Average Loss Given Default } \\
\text { (as a fraction of the initial annuity portfolio value) }\end{array}$} \\
\cline { 1 - 3 } Strategy & No Natural Hedging & & Natural Hedging \\
\cline { 2 - 3 } \cline { 5 - 6 } & $\begin{array}{c}1000 \\
\text { Annuitants }\end{array}$ & $\begin{array}{c}50000 \\
\text { Annuitants }\end{array}$ & & $\begin{array}{c}1000 \\
\text { Annuitants }\end{array}$ & $\begin{array}{c}50000 \\
\text { Annuitants }\end{array}$ \\
\hline DFDH & $12.14 \%$ & $11.83 \%$ & & $15.10 \%$ & $6.07 \%$ \\
$80 \%-20 \%$ & $12.82 \%$ & $12.62 \%$ & & $20.07 \%$ & $13.60 \%$ \\
$50 \%-50 \%$ & $18.89 \%$ & $18.52 \%$ & & $30.43 \%$ & $21.41 \%$ \\
$20 \%-80 \%$ & $24.36 \%$ & $24.07 \%$ & & $39.35 \%$ & $27.85 \%$ \\
\hline
\end{tabular}

Table 9: The table shows, given 10000 simulated paths of the market values of assets and liabilities for the 1000 annuity contracts and 50000 annuity contracts portfolio, the average loss in case of default as a percentage of the initial portfolio value with and without natural hedging.

9 as a percentage of the initial liability annuity portfolio value, which is the value of the position to hedge, confirms our results: the average loss in case of bankruptcy is higher for small portfolios and riskier strategies and it is worsened by the natural hedging strategy, unless idiosyncratic risk is well-diversified and interest-rate risk is properly accounted for.

\section{Concluding comments}

Our paper studies the effectiveness of natural hedging in an insurance portfolio in run-off. We take an asset-liability management perspective and account for the impact of equity risk, interest-rate risk and both systematic and idiosyncratic longevity risk on the solvency of the portfolio. Our a continuoustime cohort-based modelling of longevity risk allows us to obtain the values of standard insurance contracts in closed-form, reducing computational effort despite our comprehensive description of the risk processes.

Our analysis documents first of all the relevant contribution of systematic longevity risk to the variability of the value of an annuity portfolio, suggesting that managing it is of utmost importance for insurance companies and pension funds. The market-consistent valuation of liabilities requires considering both the asset mix and the liability mix decisions as interconnected. We find, consistently with the empirical findings in Cox and Lin (2007), that companies implementing natural hedging strategies can charge a lower 
premium to their annuitants, when they have to meet a solvency requirement. This happens in particular for well-diversified portfolios and when managers implement less risky investment strategies. Moreover, we stress the importance of implementing LDI hedging strategies, and the need to manage simultaneously the interest-rate risk and the longevity risk profile of the insurer.

\section{References}

Biffis, E. (2005). Affine processes for dynamic mortality and actuarial valuations. Insurance: Mathematics and Economics 37(3), 443-468.

Biffis, E. and D. Blake (2013). Informed intermediation of longevity exposures. The Journal of Risk and Insurance 80, 559-584.

Blake, D., R. MacMinn, J. Li, and M. Hardy (2014). Longevity risk and capital markets: The 2012-2013 update. North American Actuarial Journal 18, $1-13$.

Cox, S. and Y. Lin (2007). Natural hedging of life and annuity mortality risks. North American Actuarial Journal 11, 1-15.

Dahl, M. and T. Møller (2006). Valuation and hedging of life insurance liabilities with systematic mortality risk. Insurance: Mathematics and Economics 39(2), 193-217.

Duffie, D., J. Pan, and K. Singleton (2000). Transform Analysis and Asset Pricing for Affine Jump-Diffusions. Econometrica 68(6), 1343-1376.

Gatzert, N. and H. Wesker (2012). The impact of natural hedging on a life insurer's risk situation. The Journal of Risk Finance 13, 396-423.

Hari, N., A. De Waegenere, B. Melenberg, and T. Nijman (2008). Longevity risk in portfolios of pension annuities. Insurance: Mathematics and Economics 42, 505-519.

Human Mortality Database (2010). University of California, Berkeley (USA) and Max Planck Institute for Demographic Research (Germany). Available at www.mortality.org (data downloaded on 11/03/2010). 
Jarrow, R. and S. Turnbull (1994). Delta, gamma and bucket hedging of interest rate derivatives. Applied Mathematical Finance 1, 21-48.

Luciano, E. and L. Regis (2014). Efficient versus inefficient hedging strategies in the presence of financial and longevity (value at) risk. Insurance: Mathematics and Economics 55, 68-77.

Luciano, E., L. Regis, and E. Vigna (2012). Single and cross-generation natural hedging of longevity and financial risk. Carlo Alberto Notebook, n.257.

Luciano, E. and E. Vigna (2008). Mortality risk via affine stochastic intensities: calibration and empirical relevance. Belgian Actuarial Bulletin 8(1), $5-16$.

Mercer. Asset allocation survey, european institutional marketplace overview 2013. http://www.mercer. com/referencecontent.htm?idContent= 1462945 .

Milevsky, M. and D. Promislow (2001). Mortality derivatives and the option to annuitise. Insurance: Mathematics and Economics 29(3), 299-318.

Ngai, A. and M. Sherris (2011). Longevity risk management for life and variable annuities: the effectiveness of static hedging using longevity bonds and derivatives. Insurance: Mathematics and Economics (49), 100-114.

Olivieri, A. and E. Pitacco (2002). Solvency requirements for pension annuities. Journal of Pension Economics and Finance 2(2), 127-157.

ONS. National population projections.

Pitacco, E., M. Denuit, S. Haberman, and A. Olivieri (2009). Modelling Longevity Dynamics for Pensions and Annuity Business. Oxford University Press.

Stevens, R., A. De Waegenaere, and B. Melenberg (2011). Longevity risk and natural hedge potential in portfolios of life insurance products: the effect of investment risk. CentER Discussion Paper 2011-036.

UN. World population prospectus. http://esa.un.org/unpd/wpp/unpp/ panel\_population.html. 
Vasicek, O. (1977). An equilibrium characterization of the term structure. Journal of financial economics 5(2), 177-188.

Wang, C., H. Huang, and D. Hong (2013). A feasible natural hedging strategy for insurance companies. Insurance: Mathematics and Economics (52), $532-541$.

Wang, J., H. Huang, S. Yang, and J. Tsai (2010). An optimal product mix for hedging longevity risk in life insurance companies: the immunization theory approach. The Journal of Risk and Insurance 77(2), 473-497. 


\section{Appendix - Delta-hedging strategies}

In this Appendix we briefly describe the implementation of Delta-hedging strategies of longevity and interest-rate risk, as proposed by Luciano et al. (2012). Let us first define, following Jarrow and Turnbull (1994) the interestrate risk factor $K(t)$

$$
K(t)=r(t)-F(0, t),
$$

where $F(0, t)$ denotes the forward interest rate applying at $t$, as agreed at time 0. Analogously, we define the mortality risk factor $I(t)$

$$
I(t)=\lambda_{x}(t)-f_{x}(0, t)
$$

where $f(0, t)$ denotes the instantaneous forward mortality intensity.

Having identified these risk factors, it is possible to express the dynamics of the prospective reserves (fair-values) of annuities and life insurance policies in terms of the first and second order sensitivities (Greeks) of survival probabilities and bond prices with respect to such factors $K$ and $I$. We define the following sensitivities

$$
\begin{aligned}
\Delta^{M}(t, T) & =\frac{\partial S}{\partial I}=-S(t, T) X(t, T)<0, \\
\Gamma^{M}(t, T) & =\frac{\partial^{2} S}{\partial I^{2}}=S(t, T) X^{2}(t, T)>0, \\
\Delta^{F}(t, T) & =\frac{\partial B}{\partial K}=-B(t, T) \bar{X}(t, T)<0, \\
\Gamma^{F}(t, T) & =\frac{\partial^{2} B}{\partial K^{2}}=B(t, T) \bar{X}^{2}(t, T)>0 .
\end{aligned}
$$

The superscript $M$ denotes Greeks with respect to the mortality risk factor, while $F$ the denotes financial ones. The dynamics of a pure endowment policy $E$, having fair value $E\left(t, T_{E}\right)=S\left(t, T_{E}\right) B\left(t, T_{E}\right)$ which is the building block of annuities and life insurance policies, can be expressed, for fixed $t$, as

$$
d Z_{E}=\Delta_{E}^{M} \Delta I+\frac{1}{2} \Gamma_{E}^{M} \Delta I^{2}+\Delta_{E}^{F} \Delta K+\frac{1}{2} \Gamma_{E}^{F} \Delta K^{2}
$$

where

$$
\begin{aligned}
\Delta_{E}^{M}(t, T) & =B(t, T) \Delta^{M}(t, T)<0 \\
\Gamma_{E}^{M}(t, T) & =B(t, T) \Gamma^{M}(t, T)>0 \\
\Delta_{E}^{F}(t, T) & =S(t, T) \Delta^{F}(t, T)<0 \\
\Gamma_{E}^{F}(t, T) & =S(t, T) \Gamma^{F}(t, T)>0 .
\end{aligned}
$$


It follows that the change in the reserve of a whole-life annuity, $Z_{A}$, can be expressed as

$$
\begin{aligned}
d Z_{A} & =R\left[\Delta_{A}^{M} \Delta I+\frac{1}{2} \Gamma_{A}^{M} \Delta I^{2}+\Delta_{A}^{F} \Delta K+\frac{1}{2} \Gamma_{A}^{F} \Delta K^{2}\right] \\
\Delta_{A}^{M}(t, T) & =-\sum_{u=1}^{T-t} B_{t, u} S_{t, u} X_{t, u}=\sum_{u=1}^{T-t} \Delta_{E}^{M}(t, t+u)<0 \\
\Gamma_{A}^{M}(t, T) & =\sum_{u=1}^{T-t} B_{t, u} S_{t, u}\left[X_{t, u}\right]^{2}=\sum_{u=1}^{T-t} \Gamma_{E}^{M}(t, t+u)>0 \\
\Delta_{A}^{F}(t, T) & =-\sum_{u=1}^{T-t} B_{t, u} S_{t, u} \bar{X}_{t, u}=\sum_{u=1}^{T-t} \Delta_{E}^{F}(t, t+u)<0, \\
\Gamma_{A}^{F}(t, T) & =\sum_{u=1}^{T-t} B_{t, u} S_{t, u}\left[\bar{X}_{t, u}\right]^{2}=\sum_{u=1}^{T-t} \Gamma_{E}^{F}(t, t+u)>0 .
\end{aligned}
$$

Analogously, the change in the reserve $Z_{D}$ of a life insurance policy at time $t$ is

$$
\begin{aligned}
d Z_{D} & =C\left[\Delta_{D}^{M} \Delta I+\frac{1}{2} \Gamma_{D}^{M} \Delta I^{2}+\Delta_{D}^{F} \Delta K+\frac{1}{2} \Gamma_{D}^{F} \Delta K^{2}\right] \\
\Delta_{D}^{M}(t, T) & =\sum_{u=1}^{T-t} B_{t, u}\left(\Delta_{t, u-1}^{M}-\Delta_{t, u}^{M}\right)>0 \\
\Gamma_{D}^{M}(t, T) & =\sum_{u=1}^{T-t} B_{t, u}\left(\Gamma_{t, u-1}^{M}-\Gamma_{t, u}^{M}\right)<0 \\
\Delta_{D}^{F}(t, T) & =\sum_{u=1}^{T-t}\left(S_{t, u-1}-S_{t, u}\right) \Delta_{t, u}^{F}<0 \\
\Gamma_{D}^{F}(t, T) & =\sum_{u=1}^{T-t}\left(S_{t, u-1}-S_{t, u}\right) \Gamma_{t, u}^{F}>0 .
\end{aligned}
$$

The signs of the Greeks with respect to mortality of the two types of policies are opposite. This opens up the possibility of natural hedging. However, since financial Greeks have the same signs, it is necessary to have in mind that additional interest-rate risk might be originated when trying to neutralize systematic longevity. 
Delta-Gamma hedging strategies can be implemented by neutralizing the total sensitivity of the insurance portfolio with respect to the risk factors. It is sufficient to solve a system of linear equations to neutralize the instantaneous exposure of the portfolio. Given $N$ types of instruments in the portfolio (being either bonds, annuities or life insurance policies), it is necessary to compute the quantities $n_{i}, i=1, \ldots N$ of $\mathrm{N}$ products with maturities $T_{i}, i=1, \ldots, N$ that solve the following system

$$
\left\{\begin{array}{l}
\sum_{i=1}^{N} n_{i} \Delta_{i}^{M, j}\left(t, T_{i}\right)=0 \\
\sum_{i=1}^{N} n_{i} \Delta_{i}^{F}\left(t, T_{i}\right)=0 \\
\sum_{i=1}^{N} n_{i} \Gamma_{i}^{M, j}\left(t, T_{i}\right)=0 \\
\sum_{i=1}^{N} n_{i} \Gamma_{i}^{F}\left(t, T_{i}\right)=0
\end{array}\right.
$$

An additional requirement is needed to construct self-financing strategies. In the paper, we implement Delta-hedging strategies, which solve either equations (8a) and/or (8b), in the case in which we have one annuity and one life insurance contract. The following sections describe the strategies we consider in our numerical analysis.

\section{Natural Longevity Delta-hedging strategy}

We implement the natural Delta-hedging strategy for longevity risk at $t_{0}$, requiring

$$
\begin{gathered}
-N_{A} R \Delta_{A}^{M}\left(t_{0}, t_{0}+T_{\omega}\right)-N_{D} C \Delta_{D}^{M}\left(t_{0}, T_{D}\right)=0, \\
N_{D}=-N_{A} \frac{\Delta_{A}^{M}\left(t_{0}, t_{0}+T_{\omega}\right)}{C \Delta_{D}^{M}\left(t_{0}, T_{D}\right)}>0,
\end{gathered}
$$

where $T_{D}$ denotes the maturity of the life insurance contract, $T_{\omega}\left(t_{i}\right)=t_{\omega}-t_{i}$ the time distance to the terminal age $\omega$ of the annuitant. The negative signs in front of $N_{A}$ and $N_{D}$ mean that the insurance company has issued the policies and owns their obligations.

$N_{D}$ is the number of life insurance policies that an insurance company has to issue in order to implement the Delta-hedging strategy and it is positive, as soon as $N_{A}>0$, since the ratio of $\Delta_{A}^{M}(\cdot)$ and $\Delta_{D}^{M}(\cdot)$ is negative. In Section 3, we consider a static hedging strategy for longevity, constructing the instaneously hedged liability portfolio at zero. The strategy is not rebalanced further. Notice that the presence of bonds does not affect the portfolio 
sensitivities with respect to the longevity risk factors, as their prices are not affected by mortality rates.

\section{DFDH strategy}

The dynamic financial Delta-hedging strategy we implement neutralizes the exposure with respect to interest-rate risk at each time $t_{i}$ by neutralizing the exposure of the liability portfolio through bond purchase. At each $t_{i}$, we select the number of bonds $N_{B}\left(t_{i}\right)$ such that

$-N_{A}\left(t_{i}\right) R \Delta_{A}^{F}\left(t_{i}, t_{i}+T_{\omega}\left(t_{i}\right)\right)-N_{D}\left(t_{i}\right) C \Delta_{D}^{F}\left(t_{i}, T_{D}-t_{i}\right)+N_{B}\left(t_{i}\right) \Delta^{F}\left(t_{i}, T_{B}\right)=0$.

The negative signs in front of $N_{A}$ and $N_{D}$ mean that the insurance company has sold the policies, while the positive sign in front of $N_{B}$ means that the company has to purchase bonds. It follows that

$$
N_{B}\left(t_{i}\right)=\frac{N_{A}\left(t_{i}\right) R \Delta_{A}^{F}\left(t_{i}, t_{i}+T_{\omega}\left(t_{i}\right)\right)+N_{D}\left(t_{i}\right) C \Delta_{D}^{F}\left(t_{i}, T_{D}-t_{i}\right)}{\Delta^{F}\left(t_{i}, T_{B}\right)}>0
$$

which is positive since both the numerator and the denominator are negative. When the number of bonds $N_{B}\left(t_{i}\right)$ can not be purchased because the insurance company lacks the necessary amount of funds, the company buys as many bonds as possible, investing in all the available funds in the bond market. 


\section{Institution Markets \\ IMT}

INSTITUTE FOR ADVANCED STUDIES LUCCA

2014 ( ) IMT Institute for Advanced Studies, Lucca Piazza San Ponziano 6, 5100 Lucca, Italy. www.imtlucca.it 